\title{
ESTUDO DOS IMPACTOS DA SECAGEM DA MICROALGA Spirulina platensis EM ESTUFA
}

\author{
L.V.D. FREITAS ${ }^{1}$, A. O. SANTOS $^{1}$, N. C. SILVA $^{1}$, C. R. DUARTE ${ }^{1}$ e M. A. S. BARROZO ${ }^{1}$ \\ ${ }^{1}$ Universidade Federal de Uberlândia, Faculdade de Engenharia Química \\ E-mail para contato: luis_victor695@hotmail.com
}

RESUMO - As microalgas são organismos fotossintéticos microscópicos que possuem alto potencial nutritivo e dentre as suas vantagens está a não competição com as culturas alimentares tradicionais. Por representarem uma biomassa de alta umidade, a secagem surge como técnica para conservação e posterior utilização das microalgas como alimento, a fim de aproveitar as suas propriedades nutricionais que incluem a presença de diversos compostos bioativos benéficos à saúde humana. Dentro do exposto, o presente trabalho avaliou a viabilidade da secagem da microalga Spirulina platensis por estufa em diferentes temperaturas e o impacto do processo nos seus compostos bioativos. Verificou-se que o uso da estufa para secagem da Spirulina se mostrou eficiente e se realizado em temperaturas adequadas, pode ser favorável aos teores de bioativos presentes nesse material.

\section{INTRODUÇÃO}

A população do planeta cresce cerca de 83 milhões de pessoas por ano e estima-se que a população mundial alcançará o valor de 9 bilhões de pessoas em 2050, um aumento de 2 bilhões em relação a população atual. Para suprir a demanda de alimento seria necessário duplicar, senão triplicar a produção agrícola nos próximos 33 anos (Kinkartz, 2011). Assim, buscam-se alternativas viáveis para sanar a escassez mundial de alimentos, dentre elas uma possível solução estaria no meio aquático, uma vez que a disponibilidade de terrenos para agricultura e pecuária é limitada e aproximadamente $75 \%$ do planeta Terra é formado por água (Oliveira, 2016).

Microalgas são organismos fotossintéticos microscópicos que se encontram distribuídos tanto em águas doces como em águas salgadas (Sousa, 2014). As algas apresentam vantagens às plantas comuns, dentre elas: um rápido crescimento de algumas espécies (o que proporciona maior produtividade) apresenta estrutura unicelular (o que confere mesma composição bioquímica) e através da manipulação do meio de cultivo há também a viabilidade de incitar à maior síntese ou maior acúmulo de compostos de interesse (Costa, 2014; Derner, 2006).

A Spirulina platensis é uma espécie de microalga que apresenta de maneira equilibrada diversos constituintes capazes de substituir fontes artificiais de nutrientes. Em razão de sua composição variada, como seu alto teor proteico (60-70\%) e a presença de pró-vitaminas, minerais e ácidos graxos poli-insaturados esta microalga tem ganhado atenção devido suas propriedades nutricionais e medicinais. As suas propriedades terapêuticas estão associadas à presença de compostos antioxidantes, tais como ficocianina e fenólicos (Ambrosi, 2008; Costa, 2014; Miranda et al., 1998). 
Devido a sua alta porcentagem de água, a Spirulina é susceptível ao crescimento microbiano e rápida deterioração, por isto uma técnica de conservação se faz necessária e assim, a secagem surge como alternativa. Dentre as vantagens de se desidratar um alimento estão: prolongar a vida de estocagem de um produto (com baixo teor de umidade o risco de oxidação e ações enzimáticas diminuem), agregar valor (muitas qualidades e compostos nutricionais importantes podem ser intensificados pela secagem), facilidade no manuseio e embalagem do produto (geralmente um produto seco ocupa menor volume e peso) e esterilização do material, pois após passar pelo processo térmico micro-organismos presentes podem ser destruídos (Mujumdar, 2006).

Dentro do exposto, este trabalho avaliou a viabilidade da secagem da microalga Spirulina platensis pelo método da estufa juntamente com o impacto da técnica em alguns de seus compostos bioativos (fenólicos, flavonoides, ácido cítrico e ficocianina).

\section{MATERIAIS E MÉTODOS}

\subsection{Material Utilizado e Aparato Experimental}

A microalga Spirulina platensis foi fornecida pela empresa Brasil Vital, localizada em Anápolis, no Estado de Goiás. A empresa forneceu as amostras previamente filtradas, as quais foram separadas, empacotadas e congeladas em freezer à $-18^{\circ} \mathrm{C}$, onde ficavam até o momento dos experimentos (Figura 1). Nos dias em que os experimentos eram realizados, retiravam-se as amostras do freezer cerca de 4 horas antes do início das atividades, as quais eram deixadas para descongelar a temperatura ambiente. Após a secagem, adotava-se o mesmo método de armazenamento do material, embalando-o o até o momento da realização das análises.

Figura 1 - Amostras de Spirulina platensis
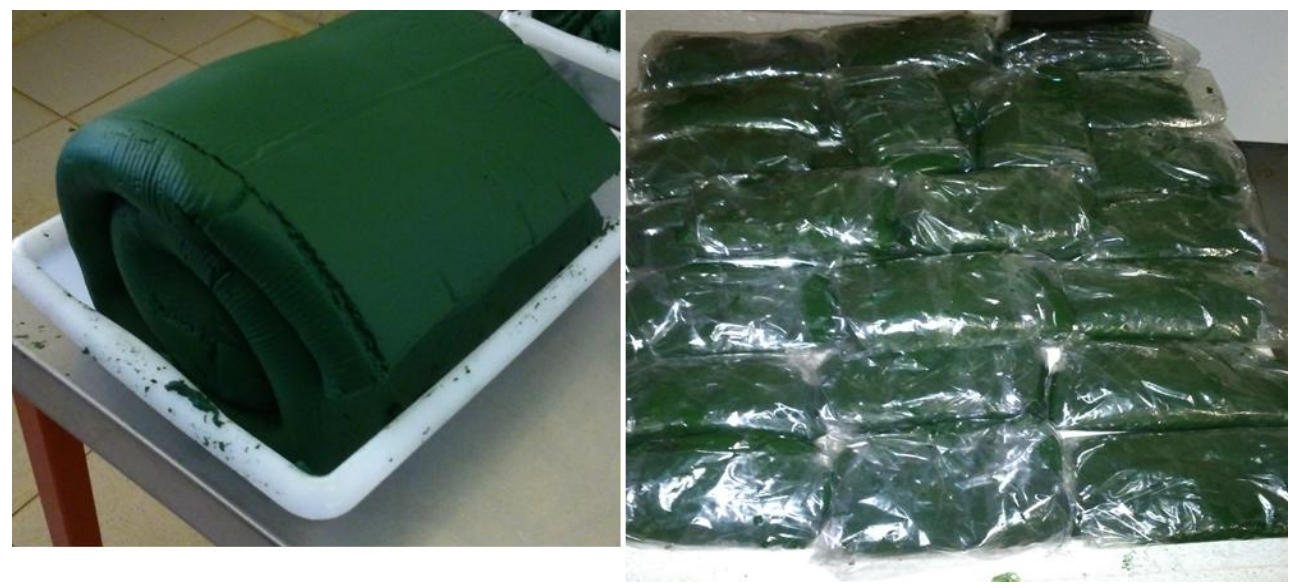

A secagem foi realizada em estufa de convecção forçada (Marconi - Modelo MA033). $\mathrm{O}$ material foi desidratado nas temperaturas de $60^{\circ} \mathrm{C}, 75^{\circ} \mathrm{C}, 90^{\circ} \mathrm{C}$, e $105^{\circ} \mathrm{C}$. Em cada experimento, as amostras foram colocadas distribuídas uniformemente sobre uma placa de petri, retiradas e pesadas a cada 20 minutos para controle da remoção de umidade. Os experimentos foram finalizados quando esta variação de massa fosse desprezível. Ao término dos experimentos, o teor de umidade foi determinado através método da estufa $105 \pm 3{ }^{\circ} \mathrm{C}$ por 
24 horas (AOAC, 1995) e a atividade de água (Aw) foi medida pelo equipamento Lab-Swift AW (Novasina).

\subsection{Análise dos compostos bioativos}

Os compostos bioativos foram verificados tanto para a microalga in natura quanto para as amostras desidratadas. Realizaram-se as seguintes análises físico-químicas (todas em triplicata):

Teor de Fenólicos totais (TPC): Determinado pelo método de Folin Ciocalteau (Singleton \& Rossi, 1965), usando ácido gálico como curva padrão de comparação no espectrofotômetro. É expresso em mg ácido gálico / $100 \mathrm{~g}$ de amostra em base seca;

Teor de Flavonoides totais (TFC): O conteúdo de flavonoides totais foi determinado pelo método colorimétrico descrito por Zhishen et al. (1999). Utilizou-se leitura em espectrofotômetro utilizando curva padrão de rutina e os resultados foram expressos em mg de rutina / $100 \mathrm{~g}$ de amostra em base seca;

Acidez ou Acidez total titulável (ATT): Expressa através do teor de ácido cítrico presente na amostra, foi obtida através da titulação com $\mathrm{NaOH}$ padronizado, com os resultados expressos em mg ácido cítrico / $100 \mathrm{~g}$ amostra em base seca (AOAC, 1995);

Teor de Ficocianina (TF): O teor de ficocianina foi determinado de acordo com exposto por Costa (2014). As amostras foram lidas em espectrofotômetro nas absorbâncias de 620 e $652 \mathrm{~nm}$. Os resultados foram expressos em g ficocianina/ 100g amostra em base seca.

\section{RESULTADOS E DISCUSSÕES}

Os teores dos compostos bioativos encontrados na Spirulina in natura estão expressos na Tabela 1. Comprovou-se que como discutido anteriormente, esta microalga possui uma alta porcentagem de umidade e quantidade considerável de compostos bioativos, o que evidencia a necessidade de um devido aproveitamento da mesma.

Tabela 1 - Compostos bioativos e umidade para a Spirulina in natura.

\begin{tabular}{|c|c|}
\hline Análises & Resultados* \\
\hline Fenólicos (TPC) & $252,40 \pm 13,77 \mathrm{mg}$ de ácido gálico \\
\hline Flavonoides (TFC) & $4,83 \pm 0,25 \mathrm{mg}$ rutina \\
\hline Acidez (AA) & $2173,68 \pm 179,32 \mathrm{mg}$ ácido cítrico \\
\hline Ficocianina (TF) & $8,75 \pm 0,51 \mathrm{~g}$ ficocianina \\
\hline Umidade & $82,40 \pm 0,40 \%$ \\
\hline
\end{tabular}

*Resultados /100g de amostra em base seca

\subsection{Umidade Final e Atividade de Água}

Os resultados de umidade final, atividade de água e tempo de secagem obtidos nos experimentos estão expressos na Tabela 2. A atividade de água é um dos fatores predominantes na indústria, através dele é possível prever a estabilidade dos alimentos, ou 
seja, quantificar a água disponível para o crescimento microbiótico e as reações capazes de alterar os alimentos. Estima-se que ocorra mínimo ou nenhum crescimento de microrganismos quando a atividade de água estiver próxima de 0,6 (Celestino, 2010).

Verificou-se assim que em todas as temperaturas avaliadas, a atividade de água (Aw) atingiu valores satisfatórios e à medida que os experimentos foram conduzidos em temperaturas maiores, os valores de Aw diminuíram juntamente com a umidade final e o tempo de secagem. Entretanto, torna-se necessário verificar se em maiores temperaturas não houve impacto nos teores de compostos bioativos.

Tabela 2 - Umidade final e Atividade de Água da Spirulina após as secagens.

\begin{tabular}{|c|c|c|c|}
\hline $\begin{array}{c}\text { Temperatura } \\
\left({ }^{\circ} \mathrm{C}\right)\end{array}$ & $\begin{array}{c}\text { Umidade Final } \\
(\%)\end{array}$ & $\begin{array}{c}\text { Atividade de Água } \\
(\mathrm{Aw})\end{array}$ & $\begin{array}{c}\text { Tempo de Secagem } \\
(\mathrm{min})\end{array}$ \\
\hline 60 & $16,99 \pm 0,10$ & 0,581 & 720 \\
\hline 75 & $13,08 \pm 0,12$ & 0,524 & 460 \\
\hline 90 & $6,28 \pm 0,38$ & 0,335 & 300 \\
\hline 105 & $5,44 \pm 0,18$ & 0,297 & 220 \\
\hline
\end{tabular}

\subsection{Compostos Bioativos}

Os resultados obtidos para os teores totais de fenólicos (TPC) e flavonoides (TFC) estão expressos na Figura 2.

Figura 2 - Teor de Fenólicos Totais (TPC) (a) e Teor de Flavonoides Totais (TFC) (b)
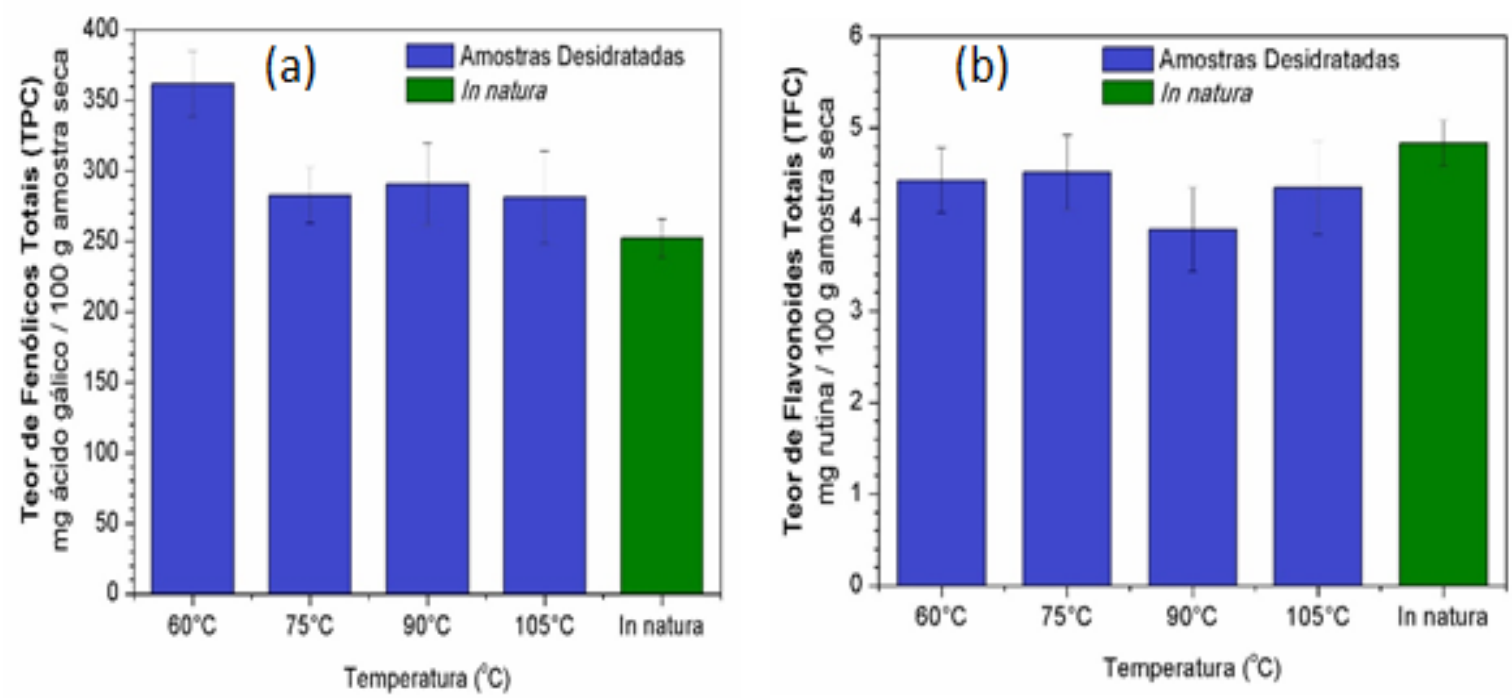

Através dos resultados expostos na Figura 2a, averiguou-se que os teores dos compostos fenólicos foram próximos ou até superiores daqueles encontrados no material in natura. Uma possível explicação para tal comportamento é que há uma liberação desses compostos devido ao rompimento da matriz interna do material durante a remoção de umidade, como relatado por Chism e Haard (1996). Observou-se que o melhor resultado foi obtido na temperatura de $60^{\circ} \mathrm{C}$, mesmo tendo o maior tempo de secagem o que indica que a Spirulina foi mais afetada 
pela temperatura do que pelo tempo de exposição. Nas demais temperaturas os resultados foram praticamente constantes, indicando que os teores de fenólicos não foram impactados negativamente pela remoção de umidade.

Na Figura 2b, estão expostos os resultados de TFC para todas as condições analisadas, onde se verificou que os teores de flavonoides se mantiveram praticamente constantes independentes da temperatura e do tempo de secagem. Os resultados foram bem próximos dos obtidos para o material in natura, o que indica pouco impacto da técnica de secagem nestes compostos.

Figura 3 - Acidez (ATT) (a) e Teor de Ficocianina (TF) (b)
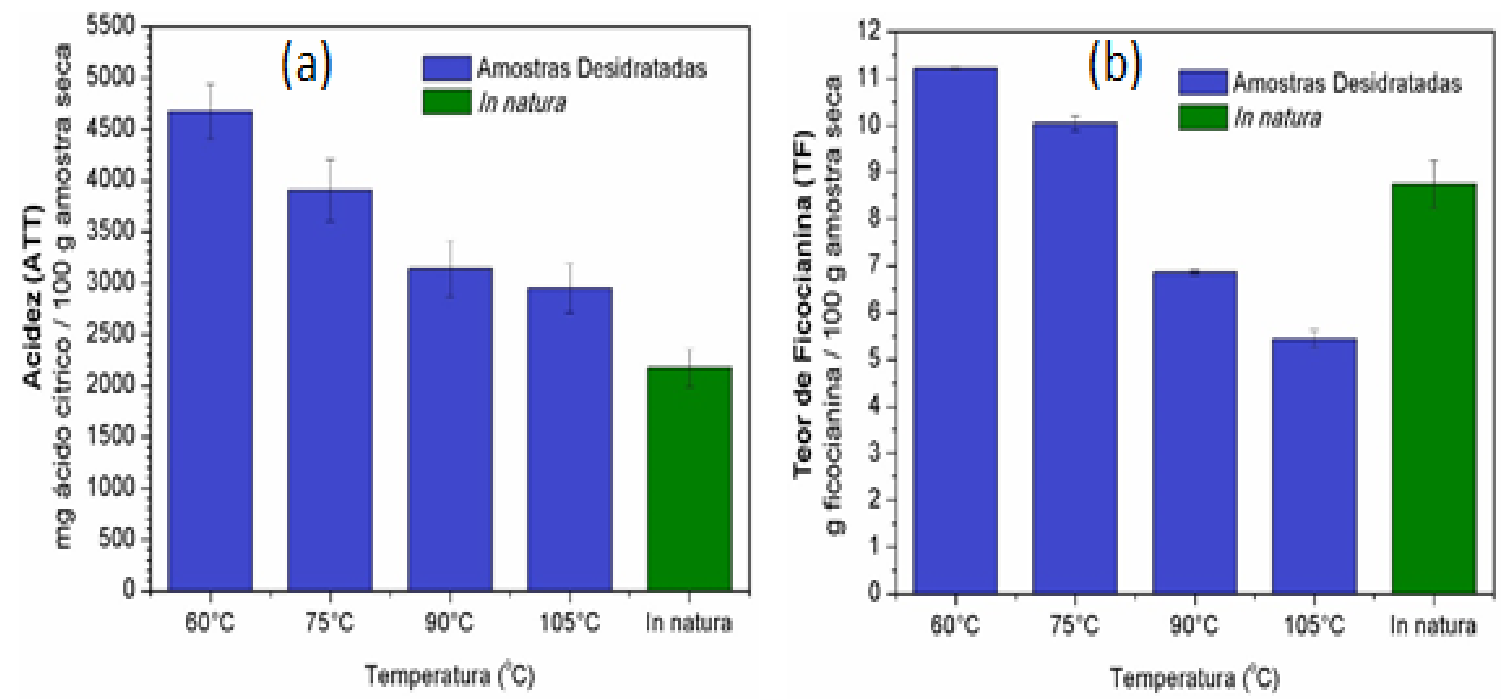

Os teores de ácido cítrico (ATT) estão expressos na Figura 3a. Verificou-se que à medida que os experimentos foram conduzidos em maiores temperaturas, houve maior degradação do composto. Conforme observado por Podsedek (2007) o ácido cítrico apresenta certa sensibilidade quando exposto a temperaturas elevadas. Portanto, a melhor condição foi a de $60^{\circ} \mathrm{C}$ onde foi possível obter teores acima do material antes de ser desidratado, indicando uma possível liberação ao longo do processo (Chism e Haard, 1996).

$\mathrm{Na}$ figura $3 \mathrm{~b}$ estão apresentados os teores de ficocianina (TF). Observou-se que assim como o ácido cítrico, a ficocianina é um composto termossensível, impactado diretamente e negativamente pelo aumento da temperatura de secagem (Oliveira, 2016). Outro ponto importante a se ressaltar é que, conforme exposto por Martelli et. al. (2014) a ficocianina é ligeiramente mais estável em condições ácidas. Desta forma, ao se comparar os resultados obtidos na Figura 2 b com $2 a$, ficou evidente que a alta acidez impactou positivamente no teor de ficocianina, tendo sua melhor condição novamente na temperatura de $60^{\circ} \mathrm{C}$.

\section{CONCLUSÃO}

A secagem da Spirulina em estufa se mostrou um método eficiente em relação à sua preservação em todas as condições analisadas, nas quais o material desidratado atingiu níveis satisfatórios de umidade e atividade de água, adequados ao amarzenamento. Embora os experimentos realizados em temperaturas maiores fornecerem menores tempos de secagem, a 
maioria dos compostos sofreu certa degradação em temperaturas superiores, evidenciando que a secagem da Spirulina em menores temperaturas, com destaque para a de $60^{\circ} \mathrm{C}$, produziu maiores teores dos compostos bioativos.

\section{REFERÊNCIAS}

AMBrosi, M. A., REINEHR, C. O., BERTOLin, T. E., COSTA, J. A. V., COLlA, L. M. Propriedades de saúde de Spirulina spp. Rev. ciênc. farm. básica apl., 29 (2), 109-117, 2008.

AOAC, Association of Official Analytical Chemists, 1995. Official Methods of Analysis, Gaithersburg, MD, 1995.

CELESTINO, S.M.C. Princípios de Secagem de Alimentos. Planaltina, DF: Embrapa Cerrados.51p, 2010.

CHISM, G. W.; HAARD, N. F. Characteristics of edible plant tissues. Food Chem., $3^{\text {a }}$ Ed., p. 943-1011. New York; Marcel Dekker, Inc, 1996.

COSTA, B. R.; PINTO, L. A. A.. Secagem da Spirulina em camada delgada utilizando secador com bomba de calor. Tese de Doutorado. Universidade Federal do Rio Grande, 2014.

DERNER, R. B. Efeito de fontes de carbono no crescimento e na composição bioquímica das microalgas Chaetoceros muellei e Thalassiosira fluviatilis, com ênfase no teor de ácidos graxos poliinsaturados. Tese de doutorado, Universidade Federal de Santa Catarina, 2006.

KINKARTZ, S. Crescimento populacional e o desafio da alimentação. In Deutsch Welle online, Akademie Journalism "Made for minds", 2011.

MARTELli, G., FOLLI, C., VISAI, L., DAGLIA, M., \& FERRARI, D. Thermal stability improvement of blue colorant C-phycocyanin from Spirulina platensis for food industry application. Process Biochem, v.49, p.154-159, 2014.

MIRANDA, M. S.; CINTRA, R. G.; BARROS, S. B. M.; MANCINI-FILHO, J. Antioxidant activity of the microalga Spirulina maxima. Braz. J. Med. Biol. Res., v. 31, p.1075-1079, 1998.

MUJUMDAR, A. S. Handbook of industrial drying. 2 ed. New York: Marcel Dekker, 1995.

OLIVEIRA, A.C.F. Desidratação Da Microalga Spirulina platensis. Monografia de Graduação. Faculdade de Engenharia Química da Universidade Federal de Uberlândia, 2016.

PODSEDEK, A. Natural Antioxidants and Antioxidant Capacity of Brassica Vegetables: A review. LWT - J. Food Compos. Anal., v.40, p.1-11, 2007.

SINGLETON, V. L.; ROSSI, J. A. Colorime-try of total phenolics with phosphomolibidic phosphotungistic acid reagents, Am. J. Enol. Vitic., 16, 144-158, 1965.

SOUSA, C. V. Microalgas: do Tratamento de Efluentes para a Biorrefinaria. Monte da Caparica. 101p, 2014.

ZHISHEN, J.; MENGCHENG, T.; JIANMING, W. The determination of flavonoid con-tents in mulberry and their scavenging effects on superoxide radicals, Food Chem., 64, 555 - 559, 1999. 